\title{
Evaluation of pharmacotherapy in inpatients with mania in bipolar disorder
}

\author{
Agnieszka Piróg-Balcerzak*, Małgorzata Rzewuska, Małgorzata Luks, Janina Skalska, Agnieszka Kałwa \\ From $1^{\text {st }}$ International Congress on Neurobiology and Clinical Psychopharmacology and European \\ Psychiatric Association Conference on Treatment Guidance \\ Thessaloniki, Greece. 19-22 November 2009
}

\section{Background}

The studies concerning prophylactic treatment in bipolar disorder suggest it should be introduced after the first manic episode [1]. Also early polytherapy is promoted, mainly mood stabilizers and antipsychotics. Antipsychotics are recommended in short-term use [2], but they are also used after improvement. Typical antipsychotics are effective in monotherapy in $70 \%$ of patients, like mood stabilizers.[3] The combination of antipsychotics and mood stabilizers is superior to monotherapy in rapid control of agitation.

\section{Materials and methods}

We determined which drugs are chosen at Institute of Psychiatry and Neurology for treating and preventing manic episodes. 61 inpatients diagnosed with manic episodes were evaluated.At discharge, $28 \%$ of patient were ordered to take one drug. For $72 \%$ patients polytherapy was ordered.

\section{Results}

There was no difference in the number of disease or manic phases between the group of patients with a remission phase lasting for at least a year and less than a year. Recurrence within one year after discharge was twice as frequent in patients with polytherapy than with monotherapy. During polytherapy the probability of avoiding recurrnce was dropping quickly.No dependence was observed between the number of recurrences at patients with monotherapy or polytherapy and such parameters as the number of manic episodes, the number of depression episodes or education.

\footnotetext{
Independent Pharmacotherapy Unit, Institute of Psychiatry and Neurology,
} Warsaw, Poland

\section{Conclusions}

In most inpatients polytherapy was applied. For the maintenance phase of treatment the same drugs were recommended as used for active treatment. The way of treatment fully corresponds to bipolar disorder treatment standards.

Published: 22 April 2010

\section{References}

1. Biel MG, Peselow E, Mulcare L, Case BG, Fieve R: Continuation versus discontinuation of lithum in reccurent bipolar illness:A naturalistic study. Bipolar Disorders 2007, 9:435-442.

2. Mendlewicz J, Souery D, Rivelli SK: Short-term and long-term treatment of bipolar patients: beyond the guidelines. J Affect Dis 1999, 55:79-85.

3. Ertugrul A, Meltzer HY: Antipsychotic drugs in bipolar disorder. Int J Neuopsychopharmacology 2003, 6:277-284.

4. Hirschfeld R, Calabrese JR, Weissman M, Frye M, Keck PE, Wagner K, Reed M: Prevalence of bipolar spectrum in US adults [abstract]. European Neuropsychopharmacology 2002, 12:218.

\section{doi:10.1186/1744-859X-9-S1-S102}

Cite this article as: Piróg-Balcerzak et al:: Evaluation of pharmacotherapy in inpatients with mania in bipolar disorder. Annals of General Psychiatry 2010 9(Suppl 1):S102.

\section{Submit your next manuscript to BioMed Central and take full advantage of: \\ - Convenient online submission \\ - Thorough peer review \\ - No space constraints or color figure charges \\ - Immediate publication on acceptance \\ - Inclusion in PubMed, CAS, Scopus and Google Scholar \\ - Research which is freely available for redistribution

